\title{
ESCOLHA PROFISSIONAL DA DOCÊNCIA: INFLUÊNCIAS MARCANTES NA OPINIÃO DE PROFESSORES DO ENSINO FUNDAMENTAL I
}

Ana Luzia Videira Parisotto, Michelle Mariana Germani, Patrícia Regina de Souza, Estela Aparecida de Souza dos Santos, Estela Lemos Moreira, Lohayna Patrícia Dias dos Santos

Universidade Estadual Paulista - UNESP, Mestrado em Educação, Presidente Prudente, SP. E-mail: analu.videira@uol.com.br. Órgão de fomento: CNPq

\section{RESUMO}

É importante dar voz aos professores, reconhecendo quais foram as pessoas que influenciaram positivamente a sua escolha profissional, pois sabemos que a profissão docente não tem sido uma carreira atraente devido a múltiplos fatores. Dessa forma, tomamos o seguinte questionamento como percurso gerador deste artigo: quais foram as pessoas que influenciaram positivamente a escolha da profissão docente? Apresentamos então um recorte de uma pesquisa maior, de base quali-quantitativa, financiada pelo $\mathrm{CNPq}$, contando com a participação de trinta e três gestores escolares e cento e cinquenta e oito docentes, de vinte e duas escolas do município de Presidente Prudente/SP. Nosso objetivo para este artigo, baseando-nos no recorte estabelecido, foi analisar, à luz da análise de conteúdo, as respostas emitidas por 158 professores, por meio da aplicação de um questionário. Os resultados apontam que, majoritariamente, o professor é a principal referência dos sujeitos pesquisados, quando a tônica é escolha da profissão.

PALAVRAS-CHAVE: Escolha profissional, formação de professores, trajetória docente, identidade profissional, ensino fundamental I.

\section{OPTING FOR TEACHING PROFESSION: MAJOR INFLUENCES FROM THE PERSPECTIVE OF ELEMENTARY SCHOOL TEACHERS}

\begin{abstract}
It is important to give voice to school teachers and acknowledge the people who positively influenced their career choice as it is well known that teaching has become an unattractive profession for many reasons. Therefore, we have employed the following question to compose this article: Who positively influenced the participating schoolteachers' career choice? This article focuses on an excerpt of a broader qualitative-quantitative research project funded by The National Council for Scientific and Technological Development (CNPq), with the participation of 33 school administrators and 158 teachers from 22 elementary schools (Grades 1-5) in the municipality of Presidente Prudente, São Paulo State, Brazil. Focusing on the aforementioned excerpt, this study aimed to analyze - by means of content analysis - the participating schoolteachers' responses to a questionnaire. On the whole, results indicate that the participants' own teachers constituted their major influence when choosing their profession.

KEYWORDS: professional choice, teacher education, teacher trajectory, professional identity, elementary school.
\end{abstract}




\section{INTRODUÇÃO}

Vários estudos têm sido realizados para melhor compreensão do campo da formação de professores, bem como com o intuito de entender quais as motivações recebidas para a escolha da profissão docente (NÓVOA, 2007; ARROYO, 2011; CUNHA, 2012; IMBERNÓN, 2005). Dessa forma, é importante dar voz aos professores reconhecendo as razões e as pessoas que influenciaram positivamente a sua escolha profissional, pois, como afirmam Raymond e Tardif (2000), o sujeito professor traz consigo um conjunto de experiências como aluno, por meio do qual vivenciou várias situações e diferentes práticas pedagógicas.

O professor, como ser humano que é, inserido em uma atividade interativa por excelência, fica à mercê de influências na formação de sua identidade. Sequer podemos dizer que tal identidade é estática e acabada, já que as realidades da sala de aula se mostram mutáveis. Certo é que a identidade docente se constrói também a partir da observação de outros professores que aplicam práticas consagradas, como se fossem um legado a outras gerações. Logo, "as opções que cada um de nós tem a fazer como professor, as quais cruzam a nossa maneira de ser com a nossa maneira de ensinar desvendam na nossa maneira de ensinar a nossa maneira de ser" (NÓVOA, 2007, p. 17).

Assim, não é possível desprezar suas crenças, suas histórias de vida ou seus incentivos, os quais acabam por constituir particularidades quando realiza as suas atividades docentes. Trata-se de pensar sobre como determinados modos de ser relacionam-se ao exercício da profissão. Loureiro (2001, p. 32) afirma que:

$A(s)$ cultura(s) dos professores não é (são) mais do que a soma do que os professores pensam, dizem e fazem, enquanto membros de uma mesma comunidade profissional. Esta decorre, por sua vez, de um conjunto de condições e processos endógenos e exógenos que vão contribuindo continuamente para a configuração e reconfiguração de sua actividade.

A diversidade dos meios que envolve a construção das identidades distintas e as diversidades culturais exigem o pensar do elemento que sente, sofre, concentra a diversidade de influências que vivencia. Por isso mesmo, o professor torna-se importante em diversos espaços associados à educação, contribuindo com a transformação do cidadão em sociedade, identificando sua posição no mundo, de acordo com Roldão (2007, p. 94): "[...] a função específica de ensinar já não é hoje definível pela simples passagem do saber não por razões ideológicas ou apenas por opções pedagógicas, mas por razões sócio-históricas". Sendo assim, a formação docente requer uma formação permanente e esforço e empenho de cada um para o aprimoramento profissional (GOERGEN, 2000).

Por conseguinte, a escolha profissional é uma das mais importantes escolhas que o sujeito realiza. Há diversos motivos e razões que induzem a fazer essa escolha de profissão, dentre eles: influência familiar e/ou profissional e a observação de outros profissionais da área, como indicam Fernandes e Ronca (2010, p. 54):

Um modelo de professor guardado na memória, por exemplo, pode levar a comportamentos e atitudes semelhantes dos alunos no futuro. Para a autora, a identidade se processa ao longo da vida, num "continuum". As experiências vividas na infância, adolescência e fase adulta, a partir das relações que o sujeito estabeleceu com os familiares, parentes, amigos, professores, auxiliariam na configuração de uma imagem e percepção de si mesmo.

Logo, "compreender, pois, a trajetória pessoal do professor é também compreender como ocorrem os processos de ensino no interior das salas de aula e, em maior escala, entender as 
relações pedagógicas e os processos de ensino de uma escola" (MUHLSTEDT, HAGEMAYER, 2015, p. 37).

Nesse sentido, é notório que a profissão docente não é uma carreira atraente devido a múltiplos fatores, sendo preponderantes as queixas que abarcam principalmente a má remuneração diante de jornadas exaustivas com péssimas condições de trabalho. Tendo-se isso por base, questionamos: o que motiva as pessoas a optarem pela carreira de professor? Quais foram as pessoas que influenciaram positivamente a escolha da profissão docente?

Portanto, apresentamos, neste artigo, um recorte de uma pesquisa maior, financiada pelo CNPq, que teve início no ano de 2015, e foi desenvolvida pelo Grupo de Pesquisa Formação de Professores e Práticas de Ensino para a Educação Básica e Superior (GP-FPPEEBS) da FCT-UNESP de Presidente Prudente/SP. A pesquisa teve como intuito refletir sobre a formação do professor dos anos iniciais do Ensino Fundamental para superação do fracasso escolar em língua materna, contando com a participação de 33 gestores escolares e 158 docentes, de 22 escolas do município de Presidente Prudente/SP.

Dessa forma, nosso objetivo para este artigo, baseando-nos no recorte estabelecido, é analisar as respostas emitidas por 158 professores, por meio da aplicação de um questionário, de modo a compreender que pessoas marcaram positivamente a trajetória de formação docente desses profissionais e os influenciaram na escolha da profissão.

\section{METODOLOGIA}

A pesquisa maior financiada pelo CNPq deu origem aos dados apresentados e discutidos neste artigo. É um estudo de base quali-quantitativa, por apresentar uma quantificação estatística com uma sólida base teórica para que possamos refletir sobre o ensino de língua materna na etapa pesquisada, ou seja, o ensino fundamental I. Todavia, julgamos pertinente a afirmação de Laville e Dione (1999), sobre as abordagens de pesquisa, quando mencionam que os conflitos entre as abordagens qualitativas e quantitativas são inúteis, pois para os autores:

A partir do momento em que a pesquisa centra-se em um problema específico, é em virtude desse problema específico que o pesquisador escolherá o procedimento mais apto, segundo ele, para chegar à compreensão visada. Poderá ser um procedimento quantitativo, qualitativo, ou uma mistura de ambos. O essencial permanecerá: que a escolha da abordagem esteja a serviço do objeto de pesquisa, e não o contrário, com o objetivo de daí tirar, o melhor possível, os saberes desejados. (LAVILLE; DIONE, 1999, p. 43)

Trabalhamos com 158 docentes, oriundos de 22 escolas municipais vinculadas à Secretaria de Educação do Município de Presidente Prudente/SP. O projeto foi aprovado pelo Comitê de Ética em Pesquisa da Faculdade de Ciências e Tecnologia - Unesp - Presidente Prudente (Protocolo 947.980), em 06/02/2015. De acordo com o já mencionado recorte para apresentação de dados, neste artigo traremos apenas os resultados relativos ao seguinte questionamento presente no questionário respondido pelos docentes: "Há pessoas que marcaram positivamente a sua trajetória de formação? Exemplifique."

Para desenvolvermos as análises, substituímos os nomes das escolas por nomes de flores, aleatoriamente e dos professores por numerais arábicos, para evitar quaisquer julgamentos ou comentários posteriores e preservar a identidade dos participantes da pesquisa, de acordo com o que preconiza o Comitê de Ética.

Os dados foram tabulados e analisados segundo a análise de conteúdo proposta por Bardin (2011) e do referencial teórico voltado para formação docente (GARCIA, HYPOLITO, VIEIRA, 2005; NÓVOA, 2007, 2009; TARDIF, 2002). 


\section{RESULTADOS}

Nesta seção, apresentaremos os dados que foram obtidos por meio de questionário, respondido por 158 professores, sobre quem marcou positivamente a trajetória de formação, conforme o gráfico, a seguir:

Gráfico 1. Há pessoas que marcaram positivamente a sua trajetória de formação?

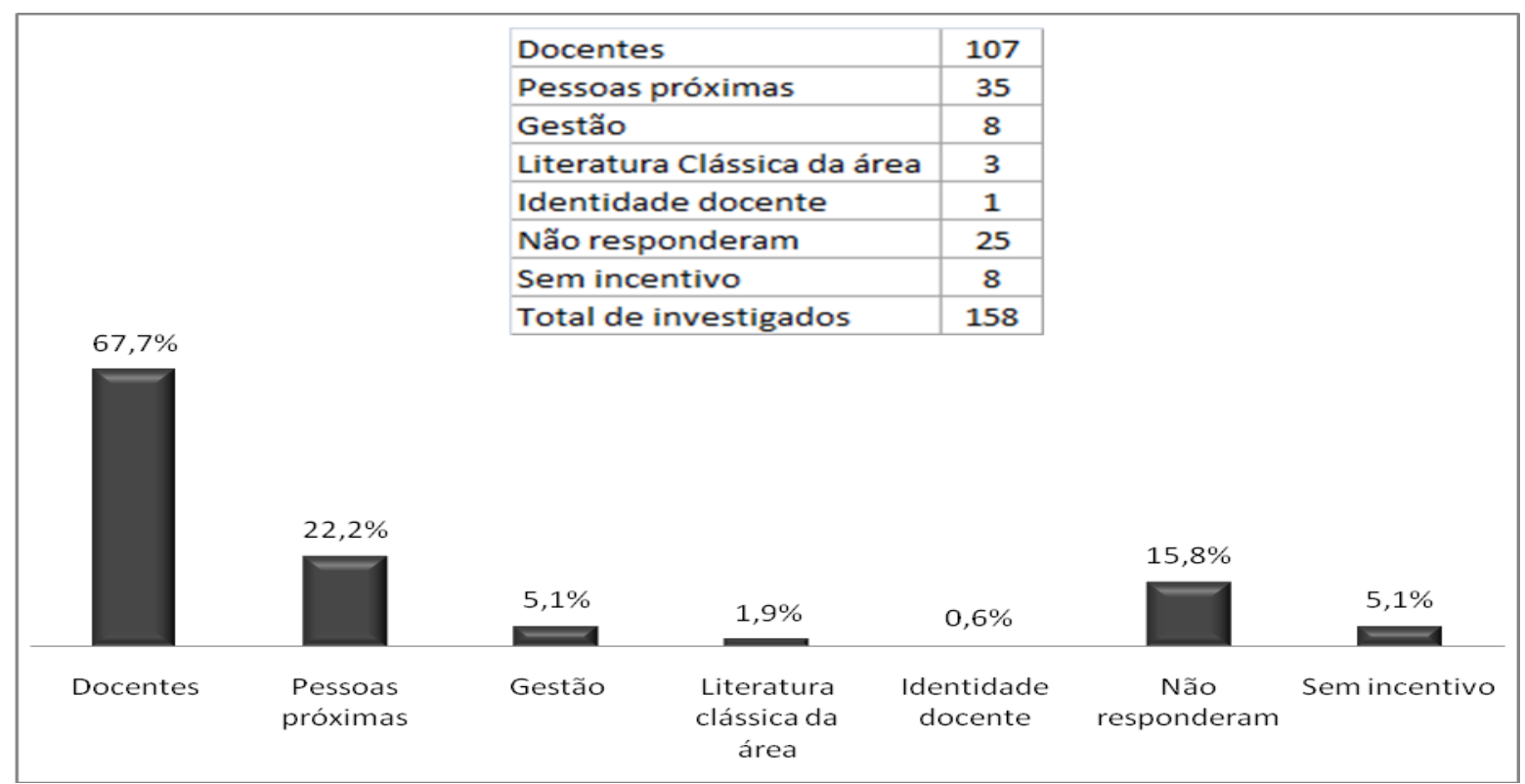

Fonte: Dados organizados pelas pesquisadoras com base nos resultados da pesquisa - 2016

Observação: As porcentagens se referem às recorrências das respostas, sendo que alguns investigados mencionaram mais de uma categoria por se tratar de uma questão aberta.

\section{DISCUSSÃO}

Pelos resultados apresentados, é perceptível que os professores se espelham em outras pessoas para o desenvolvimento da prática docente. A partir da análise do gráfico, podemos constatar que a principalmente referência costuma ser outro docente, representando $67,7 \%$. Diferentes são as razões dessa motivação: domínio da matéria ou do conteúdo, exploração de diferentes práticas pedagógicas, características pessoais positivas etc. Destacamos algumas respostas apresentadas:

Sim, professores que incentivaram e transmitiram segurança, confiança e realização pessoal. (P3, Crisântemo)

Sim. Professores empenhados, com propriedade no que falavam e, principalmente, professores que ainda mantinham contato com o ambiente escolar davam a sensação de realmente "saber" o que estavam falando/ensinando. (P1, Orquídea)

Sim, claro. Vários professores da minha graduação e pós-graduação me ajudaram na escolha da minha formação, demonstrando ter muito domínio do conteúdo e falavam com propriedade aquilo que era explicado. (P6, Orquídea)

Sim, existem professores que nos espelhamos neles. (P5, Acácia) 
Foram professoras que me deram o gosto de aprender os "porquês" dos conteúdos. (P3, Girassol)

Sim, professores dinâmicos, que dominavam o conteúdo e tinham facilidade de explicar. (P8, Alecrim)

Sim, com práticas pedagógicas diferentes. (P1, Gérbera)

Sim. Tive ótimos professores! A didática e o jeito de ser e de tratar os alunos me inspiraram. (P4, Hibisco)

Deste modo, não é qualquer professor que inspira o alunado, ou seja,

[...] os alunos tendem a reconhecer como diferenciados os profissionais que focam a relação professor-aluno e que incentivam e valorizam seu potencial, ou seja, que consideram todas as vivências, experiências e conhecimentos prévios dos discentes como caminho para o desenvolvimento e crescimento profissional, fenômeno esse já tão bem descrito pelo Educador Paulo Freire (ANDALAFT; SBRAMA, 2016, p. 81).

Nóvoa (2009) ressalta que o profissional tido como "bom professor" apresenta cinco características: conhecimento, cultura profissional, tato pedagógico, trabalho em equipe e compromisso social. Ainda, frisa que é impossível ser um professor inspirador sem uma combinação de contribuições científicas, pedagógicas e técnicas.

Além dos professores, pessoas próximas (inclusive familiares) também foram responsáveis por motivar $22,2 \%$ dos professores a optarem pela docência. Conforme se verifica nas respostas:

Sim. Na educação básica, a maioria dos meus professores mudou o rumo da minha vida. E no ensino superior encontrei muitas pessoas (colegas, amigos e docentes) que fizeram a diferença. (P5, Alecrim)

Sim, o incentivo de parentes e amigos que optaram por esta área e que se dedicam no que fazem. Eles me orientaram na trajetória de formação. (P4, Orquídea)

Sim, tenho amigas, algumas na ativa e outras aposentadas que são verdadeiras batalhadoras em prol da educação. (P1, Girassol)

Sim, mãe dava aula no sítio com turmas mistas. Eu ajudava a realizar a sopa e auxiliava na sala. (P13, Jasmim)

A influência de gestores compromissados corresponde a 5,1\% das respostas emitidas pelos professores pesquisados, ressaltando a importância de uma boa gestão escolar, conforme constatamos nas respostas:

Orientadores pedagógicos. (P7, Crisântemo)

Uma coordenadora da 2ª escola em que trabalhei. (P2, Acácia) 
Sim. Quando eu comecei na rede, a coordenadora Márcia Satomi e Maria do Carmo. (P4, Gérbera)

Sim. Minha coordenadora pedagógica e orientadora pedagógica atualmente. (P9, Gardênia)

Orientadores da rede municipal. (P2, Hibisco)

Orientadora pedagógica que trabalhou alguns anos comigo também. (P7, Hibisco)

Sim, em especial uma orientadora pedagógica. (P11, Jasmim)

Uma coordenadora de uma escola particular onde lecionei, pelo domínio, segurança e muita organização. Ela me ensinou muito. (P8, Rosa)

O incentivo de autores por meio de leitura de obras clássicas representou apenas 1,9\% das respostas, reforçando o resultado de que a influência por um contato direto é muito mais forte.

Destacamos ainda a ocorrência de uma resposta que categorizamos como identidade docente, já que o professor relacionou a motivação para a escolha profissional com o processo de construção social do sujeito professor (GARCIA; HYPÓLITO e VIEIRA, 2005). Alguns professores $(5,1 \%)$ mencionaram que não obtiveram nenhum incentivo e $15,8 \%$ dos docentes não responderam ao questionamento.

\section{CONCLUSÃO}

Por meio deste trabalho, objetivamos analisar as respostas emitidas por professores sobre as pessoas marcaram positivamente a sua trajetória de formação docente. Foi possível constatar que a identificação com a docência não se concretiza apenas com pontos de referência de outros professores, o que ficou nítido com a pesquisa que desenvolvemos, já que $5,1 \%$ dos pesquisados afirmaram que ninguém os influenciou na escolha da profissão.

Ao analisar a frequência das respostas emitidas pelos docentes, verificamos que há diferentes influências que acabaram por incidir no encaminhamento dos professores para a escolha da docência, havendo alguns que não mencionaram nenhum tipo de motivação para a escolha da profissão, porém a maior porcentagem de respostas denota que grande parte dos professores escolheu a profissão a partir de experiências com outras referências docentes com as quais tiveram contato ao longo de sua trajetória.

Dessa forma, o professor é o principal referencial dos sujeitos pesquisados, em segundo lugar, aparecem pessoas próximas, incluindo a família e, em terceiro lugar, encontramos os gestores educacionais. Assim, percebemos o quão impactante pode ser o fazer docente em sala de aula, chegando a influenciar os futuros professores, não somente com relação aos conteúdos ministrados, mas também por meio de uma motivação pessoal que os leve a se inspirar nesse docente marcante para o exercício da profissão.

\section{REFERÊNCIAS}

ANDALAFT, C. C. F.; SBRAMA, R. P. O coaching no desenvolvimento de docentes: competências que inspiram a formação de novos profissionais. UNISANTA - Humanitas. Vol. 5, n. 1, 2016, p. 6886.

ARROYO, M. G. Oficio de Mestre. 13. ed. Petrópolis: Vozes, 2011. 
BARDIN, L. Análise de conteúdo. São Paulo: Edições 70, 2011.

CUNHA, M. I. O bom professor e a sua prática. 24. ed. São Paulo: Papirus, 2012.

FERNANDES, A. B.; RONCA, A. C. C. Profissionalidade docente no ensino superior: estudo sobre professor sem formação pedagógicas. Revista Educação em Questão. 37 vol., Natal, 2010, p. 4875.

FONTANA, R. C. Como nos tornamos professoras. Belo Horizonte: Autêntica, 2000.

GARCIA, M. M. A.; HYPOLITO, A. M.; VIEIRA, J. S. As identidades docentes como fabricação da docência. Educação e Pesquisa. São Paulo, v.31 n.1, pp.45-56, jan./mar. 2005.

GOERGEN, P. L. Competências docentes na educação do futuro: anotações sobre a formação dos professores. Revista Nuances. v. 6, 2000, p. 1-9.

IMBERNÓN, F. Formação docente e profissional: formar-se para a mudança e a incerteza. São Paulo: Cortez, 2005.

LAVILLE, C.; DIONNE, J. A construção do saber: manual de metodologia da pesquisa em ciências humanas. Porto Alegre: UFMG, 1999.

MUHLSTEDT, A.; HAGEMAYER, R. C. de C. Escolha da profissão e trajetórias de vida do professor. Cadernos de Pedagogia. São Carlos, ano 8, v, 8, n. 16, jan./jun. 2015, p. 28-39.

NÓVOA, A. Para una formación de profesores construida dentro de La profesión. Revista de Educación, 350. Set./Dez. 2009, p. 203-218.

. Vidas de professores. Porto/Portugal: Porto Editora, 2007.

RAYMOND, D; TARDIF, M. Saberes, tempo e aprendizagem do trabalho no magistério. Educação \& Sociedade, Campinas, n.73, 2000. p. 209- 244.

ROLDÃO, M. do C. Função docente: natureza e construção do conhecimento profissional. Revista

Brasileira de Educação. 12.v. 2007, p. 94-181, https://doi.org/10.1590/S141324782007000100008 .

TARDIF, M. Saberes Docentes e Formação Profissional. Petrópolis/RJ: Vozes, 2002. 